\title{
Myocardial protection by ischemic preconditioning and $\delta$-opioid receptor activation in the isolated working rat heart
}

Matthias Karck, MDa

Satonori Tanaka, MDa

Steven F. Bolling, $\mathrm{MD}^{\mathrm{b}}$

Andre Simon, $\mathrm{MD}^{\mathrm{a}}$

Tsung-Ping Su, $\mathrm{PhD}^{\mathrm{C}}$

Peter R. Oeltgen, PhDd

Axel Haverich, MDa

From the Department of Thoracic and Cardiovascular Surgery, ${ }^{\mathrm{a}}$ Hannover Medical School, Hannover, Germany; Section of Cardiac Surgery, ${ }^{b}$ University of Michigan Hospitals, Ann Arbor, Mich; National Institute on Drug Abuse, ${ }^{\mathrm{c}}$ Addiction Research Center, Baltimore, Md; and the Department of Pathology, ${ }^{\mathrm{d}}$ University of Kentucky College of Medicine, Lexington, Ky.

This study was supported by a grant from the Deutsche Forschungsgemeinschaft (Ka 1169/1-2).

Received for publication Dec 21, 2000; revisions requested Jan 25, 2001; revisions received April 19, 2001; accepted for publication April 24, 2001.

Address for reprints: Matthias Karck, MD, Department of Thoracic and Cardiovascular Surgery, Hannover Medical School, 30623 Hannover, Germany.

J Thorac Cardiovasc Surg 2001;122:986-92

Copyright (C) 2001 by The American Association for Thoracic Surgery

0022-5223/2001 $\$ 35.00+0 \quad \mathbf{1 2 / 1 / 1 1 6 9 5 0}$

doi: $10.1067 / \mathrm{mtc} .2001 .116950$
Objective: $\delta$-Opioid receptors are involved in the cardioprotective effect of ischemic preconditioning. This study was designed (1) to assess the protective capacities of ischemic preconditioning and the synthetic $\delta$-opioid receptor agonist D-Ala ${ }^{2}-\mathrm{D}$ $\mathrm{Leu}^{5}$ enkephalin (DADLE) in a functionally oriented experimental model of ischemia and reperfusion and (2) to assess whether the effects of both protective measures are similarly blocked by naloxone, a nonspecific $\delta$-opioid receptor antagonist.

Methods: Sixty-four isolated working rat hearts were subjected to 45 minutes of hypothermic ischemia at $30^{\circ} \mathrm{C}$ followed by 25 minutes of normothermic reperfusion. Rats were pretreated with DADLE ( $1 \mathrm{mg} / \mathrm{kg}$ body weight intravenously), naloxone ( $3 \mathrm{mg} / \mathrm{kg}$ body weight intravenously), or a combination thereof within 60 minutes before onset of isolated heart perfusion. During the preischemic perfusion period, 8 hearts per group were preconditioned by one cycle of 5 minutes of normothermic global ischemia and subsequent reperfusion whereas another 8 served as nonpreconditioned controls. The postischemic functional recovery of hearts and their creatine kinase leakage were determined.

Results: Pretreatment with DADLE and ischemic preconditioning improved the postischemic recovery of aortic flow when compared with nonpreconditioning $(57.7 \% \pm 4.0 \%$ and $60.8 \% \pm 4.3 \%$ vs $40.0 \% \pm 4.2 \%$ of preischemic baseline value, $P<.001)$. Combined pretreatment with DADLE before ischemic preconditioning afforded additional aortic flow recovery compared with pretreatment with DADLE alone $(68.6 \% \pm 3.3 \%$ vs $57.7 \% \pm 4.0 \%$ of preischemic baseline value; $P=.038)$. With combined pretreatment, early postischemic creatine kinase release was lower than control in hearts without pretreatment $(0.48 \pm 0.11$ vs $0.80 \pm 0.12 \mathrm{IU} / 5 \mathrm{~min}$ utes per heart; $P=.001)$. Naloxone abolished the beneficial functional effects of pretreatment with DADLE and ischemic preconditioning.

Conclusions: Pharmacologic activation of $\delta$-opioid receptors affords improvement of functional protection in isolated working rat hearts similar to that conferred by classic ischemic preconditioning. The combination of both pretreatments reduces ischemic cellular damage and further adds to postischemic functional recovery. These changes are reversed by naloxone, an observation providing evidence that ischemic preconditioning involves signaling through opioid receptors. 


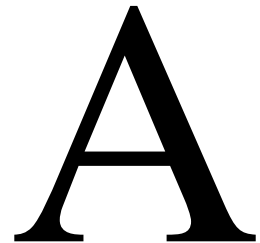

mong the current strategies to improve intraoperative cardiac protection, ischemic preconditioning has generated great interest because of its efficacy across a wide range of experimental models and animal species. $^{1,2}$ The search for pharmacologic alternatives of the classic ischemic-type stimulus revealed that direct activation of $\delta_{1}$ - and/or $\delta_{2}$-opioid receptor subtypes may similarly trigger the preconditioning pathway. ${ }^{3,4}$ Interestingly, signaling via $\delta$-opioid receptors also appears to be involved in natural mammalian hibernation biology, which parallels the altered cardiac physiology noted with hypothermia. This conclusion was derived from observations that (1) pretreatment with $\delta$-opioid receptor agonists such as D-Ala ${ }^{2}-\mathrm{D}-\mathrm{Leu}^{5}$ enkephalin (DADLE) induces hibernation-like changes in nonhibernators and that (2) hibernation can be reversed by opiate antagonists. ${ }^{5,6}$ On the basis of this coincidence, recent reports in fact suggest that natural hibernation and preconditioning share a common protective pathway via opioid receptor signaling and subsequent activation of the potassium channel. ${ }^{7}$ This and other studies on ischemic preconditioning and direct, drug-induced $\delta$-opioid receptor activation investigated the range of applications in various clinically relevant fields of myocardial protection. ${ }^{8-11}$ Commonly, study end points included markers of tissue damage such as creatine kinase leakage and infarct size with functional aspects being addressed by nonworking isolated heart preparations. In these models, however, hearts do not perform external work and their oxygen requirements are considerably less than those of the ejecting heart in vivo. ${ }^{12}$ This may limit their relevance in predicting the true postischemic capabilities to restore cardiac function, which remains the decisive quality parameter of any protective measure under investigation. We therefore used the isolated working rat heart model, which more closely resembles the conditions of the beating heart in situ. Four aspects relevant to the understanding of possible coincidence between ischemic preconditioning and drug-induced $\delta$-opioid receptor activation were addressed under functional aspects: (1) Does pharmacologic activation of the $\delta$-opioid receptor by pretreatment of the intact animal with DADLE improve cardiac function during reperfusion after hypothermic ischemia? (2) If yes, to what extent does this alteration compare with that conferred by classic ischemic preconditioning? (3) Does the nonselective opioid receptor antagonist naloxone block effects of both pretreatment with DADLE and ischemic preconditioning? (4) Do both protective measures act synergistically?

\section{Materials and Methods Perfusion Methodology}

The isolated working rat heart model was used for the purpose of this study. ${ }^{13}$ Hearts were obtained from male Wistar rats (300-400 g, Charles River, Inc, Sulzfeld, Germany). Animals were kept in a pathogen-free environment and had free access to food and water before the experiments. All animals received humane care in compliance with the "Principles of Laboratory Animal Care" formulated by the National Society for Medical Research and the "Guide for the Care and Use of Laboratory Animals" prepared by the Institute of Laboratory Animal Resources, National Research Council, and published by the National Academy Press, revised 1996.

Rats received an injection of sodium heparin (100 IU/100 g body weight intraperitoneally). After 15 minutes, the animals were anesthetized by inhalation of diethyl ether. Then, each heart was rapidly excised and placed in ice-cold saline solution. The aorta was cannulated and Langendorff perfusion was initiated at a pressure of $90 \mathrm{~cm}$ $\mathrm{H}_{2} \mathrm{O}$ with modified Krebs-Henseleit buffer containing (in millimoles per liter) $\mathrm{NaCl}, 118 ; \mathrm{KH}_{2} \mathrm{PO}_{4}, 1.2 ; \mathrm{KCl}, 4.9 ; \mathrm{CaCl}_{2}, 3 ; \mathrm{MgSO}_{4}, 1.2$; $\mathrm{NaHCO}_{3}, 25$; and glucose, 11.1. The perfusion fluids were filtered through a $5-\mu \mathrm{m}$ porosity filter to remove any particulate matter. The perfusate was aerated with a mixture of $95 \%$ oxygen and $5 \%$ carbon dioxide (pH 7.4) and the perfusate temperature was kept at $37^{\circ} \mathrm{C}$. During the time of Langendorff perfusion the left atrium was cannulated for conversion of the preparation to the working heart mode, which was achieved by stopping aortic perfusion and starting left atrial perfusion at a filling pressure of $20 \mathrm{~cm} \mathrm{H}_{2} \mathrm{O}$. Under these conditions the perfusate was ejected spontaneously at a rate of approximately $40 \mathrm{~mL} / \mathrm{min}$ through the aortic cannula against a hydrostatic pressure of $90 \mathrm{~cm} \mathrm{H}_{2} \mathrm{O}$. Hearts producing less than $37 \mathrm{~mL} / \mathrm{min}$ aortic flow were excluded from the study. Aortic flow was measured by timed collection of the ejected perfusate in a graduated cylinder. Likewise, coronary flow was measured by timed collection of the coronary effluent. Cardiac output was calculated from the sum of aortic and coronary flow. The perfusate was not recycled. After the measurement of aortic flow, a Millar Mikro-Tip catheter connected to a pressure transducer (Millar Instruments, Inc, Houston, Tex) was inserted into the left ventricle through a rubber-sealed side port of the left atrial cannula for 1 minute of data acquisition. The left ventricular pressure signal was recorded and processed online by an analogdigital converter (Plugsys; Hugo Sachs Electronic, March, Germany). Data processing was performed by an 80386 IBM-compatible personal computer equipped with standard laboratory software (Haemodyn, Hugo Sachs Electronic).

\section{Experimental Protocol}

After cannulation of the aorta, the heart was allowed to stabilize for 10 minutes in the Langendorff perfusion mode (Figure 1). After conversion to the working heart mode, the preparation was perfused for 15 minutes. Contractile function was measured and recorded. Then, hearts undergoing ischemic preconditioning (8 hearts per experimental group) were subjected to 5 minutes of global normothermic ischemia, followed by 5 minutes of Langendorff reperfusion. Hearts not undergoing preconditioning (8 hearts per experimental group) underwent 10 minutes of Langendorff perfusion instead.

Thereafter, all hearts were subjected to 45 minutes of global unprotected hypothermic ischemia at $30^{\circ} \mathrm{C}$ by stopping the perfusion and submerging the heart in perfusate at the appropriate temperature. Then, hearts were reperfused for 10 minutes in the Langendorff mode before the perfusion system was converted to the working heart mode for 15 minutes. Functional recovery was reassessed at the end of this period. Creatine kinase (CK) activity was measured in the coronary effluent collected during the initial 
TABLE 1. Preischemic functional baseline data

\begin{tabular}{lccccccc}
\hline Experimental group & IPC & $\begin{array}{c}\text { Aortic flow } \\
(\mathbf{m L} / \mathbf{m i n})\end{array}$ & $\begin{array}{c}\text { Coronary flow } \\
(\mathbf{m L} / \mathbf{m i n})\end{array}$ & $\begin{array}{c}\text { Cardiac output } \\
(\mathbf{m L} / \mathbf{m i n})\end{array}$ & $\begin{array}{c}\text { Maximum LVDP } \\
(\mathbf{m m} \mathbf{H g})\end{array}$ & $\begin{array}{c}\text { dP/dtmax } \\
\left(\mathbf{m m} \mathbf{H g} / \mathbf{s}^{2}\right)\end{array}$ & $\begin{array}{c}\text { Heart rate } \\
(\mathbf{b e a t s} / \mathbf{m i n})\end{array}$ \\
\hline 1 & - & $38.8 \pm 1.0$ & $17.2 \pm 1.4$ & $55.0 \pm 2.1$ & $150 \pm 7$ & $3993 \pm 607$ & $294 \pm 19$ \\
(Control) & + & $39.5 \pm 1.4$ & $16.7 \pm 1.9$ & $55.5 \pm 2.0$ & $140 \pm 13$ & $3783 \pm 818$ & $275 \pm 18$ \\
2 & - & $39.0 \pm 1.1$ & $19.3 \pm 0.8$ & $58.2 \pm 2.4$ & $149 \pm 5$ & $3186 \pm 466$ & $282 \pm 20$ \\
(DADLE) & + & $39.0 \pm 1.9$ & $18.8 \pm 1.3$ & $58.0 \pm 2.1$ & $151 \pm 5$ & $3287 \pm 547$ & $292 \pm 10$ \\
3 & - & $39.5 \pm 1.8$ & $19.3 \pm 1.0$ & $59.0 \pm 2.3$ & $151 \pm 5$ & $3578 \pm 288$ & $291 \pm 21$ \\
(Naloxone) & + & $39.5 \pm 2.3$ & $18.9 \pm 0.9$ & $58.5 \pm 2.7$ & $151 \pm 5$ & $3587 \pm 198$ & $288 \pm 15$ \\
4 & - & $40.0 \pm 1.2$ & $19.0 \pm 1.0$ & $58.5 \pm 2.7$ & $153 \pm 3$ & $3268 \pm 195$ & $271 \pm 7$ \\
(DADLE + naloxone) & + & $39.1 \pm 1.0$ & $18.6 \pm 0.9$ & $58.2 \pm 2.5$ & $157 \pm 4$ & $3557 \pm 153$ & $278 \pm 8$ \\
\hline
\end{tabular}

LVDP, Left ventricular developed pressure; IPC, ischemic preconditioning; DADLE, D-Ala ${ }^{2}-\mathrm{D}-\mathrm{Leu}^{5}$ enkephalin.

TABLE 2. Postischemic functional recovery rates during reperfusion following 45 minutes of hypothermic ischemia at $30^{\circ} \mathrm{C}$ (in \% of preischemic values)

\begin{tabular}{|c|c|c|c|c|c|c|c|}
\hline Experimental group & IPC & Aortic flow (\%) & Coronary flow (\%) & Cardiac output (\%) & Maximum LVDP (\%) & dP/dtmax (\%) & Heart rate (\%) \\
\hline 1 & - & $40.0 \pm 4.2$ & $81.3 \pm 12.6$ & $50.3 \pm 6.4$ & $85.6 \pm 8.0$ & $79.2 \pm 12.5$ & $95.4 \pm 6.4$ \\
\hline (Control) & + & $60.8 \pm 4.3$ & $91.0 \pm 8.7$ & $69.2 \pm 3.9$ & $92.7 \pm 5.1$ & $87.8 \pm 13.6$ & $93.1 \pm 7.7$ \\
\hline 2 & - & $57.7 \pm 4.0$ & $88.2 \pm 7.6$ & $67.1 \pm 4.5$ & $88.2 \pm 7.6$ & $77.0 \pm 9.8$ & $88.5 \pm 5.0$ \\
\hline (DADLE) & + & $68.6 \pm 3.3^{*}$ & $88.6 \pm 9.2$ & $74.1 \pm 3.1$ & $91.7 \pm 4.8$ & $84.0 \pm 8.3$ & $88.0 \pm 5.6$ \\
\hline 3 & - & $39.2 \pm 3.3$ & $83.7 \pm 4.8$ & $53.7 \pm 2.2$ & $88.4 \pm 3.4$ & $76.7 \pm 3.3$ & $86.1 \pm 5.9$ \\
\hline (Naloxone) & + & $46.1 \pm 5.6$ & $92.2 \pm 6.7$ & $61.5 \pm 5.7$ & $91.1 \pm 3.7$ & $78.1 \pm 5.0$ & $87.8 \pm 3.5$ \\
\hline 4 & - & $39.1 \pm 5.2$ & $82.3 \pm 4.5$ & $52.2 \pm 4.4$ & $87.5 \pm 2.4$ & $84.1 \pm 3.6$ & $89.4 \pm 5.5$ \\
\hline (DADLE + naloxone) & + & $42.3 \pm 4.3$ & $89.5 \pm 8.0$ & $58.8 \pm 2.8$ & $88.4 \pm 2.5$ & $76.7 \pm 6.3$ & $86.6 \pm 9.4$ \\
\hline
\end{tabular}

$\angle V D P$, Left ventricular developed pressure.

${ }^{*} P=.038$ versus "control IPC+"; mean values of recovery rates in aortic flow in groups "control IPC+," "DADLE IPC-," and "DADLE IPC+" were different from group means of all other groups $(P<.001)$.

TABLE 3. Creatine kinase leakage during the preischemic and postischemic perfusion periods

\begin{tabular}{lcccc}
\hline Experimental group & IPC & $\begin{array}{c}\text { Preischemic, working heart } \\
\text { (IU/5 min/heart) }\end{array}$ & $\begin{array}{c}\text { Postischemic, Langendorff } \\
\text { (IU/5 min/heart) }\end{array}$ & $\begin{array}{c}\text { Postischemic, working heart } \\
\text { (IU/5 min/heart) }\end{array}$ \\
\hline 1 & - & $0.25 \pm 0.03$ & $0.80 \pm 0.12$ & $0.31 \pm 0.08$ \\
(Control) & + & $0.23 \pm 0.04$ & $0.57 \pm 0.07$ & $0.44 \pm 0.11$ \\
2 & - & $0.26 \pm 0.03$ & $0.58 \pm 0.07$ & $0.37 \pm 0.08$ \\
(DADLE) & + & $0.27 \pm 0.03$ & $0.48 \pm 0.11^{*}$ & $0.36 \pm 0.07$ \\
3 & - & $0.23 \pm 0.03$ & $0.75 \pm 0.24$ & $0.39 \pm 0.12$ \\
(Naloxone) & + & $0.23 \pm 0.03$ & $0.61 \pm 0.11$ & $0.39 \pm 0.11$ \\
4 & - & $0.22 \pm 0.04$ & $0.67 \pm 0.16$ & $0.46 \pm 0.21$ \\
(DADLE + naloxone) & + & $0.22 \pm 0.05$ & $0.64 \pm 0.16$ & $0.45 \pm 0.24$ \\
\hline
\end{tabular}

$I P C$, Ischemic preconditioning; DADLE, D-Ala ${ }^{2}-\mathrm{D}-\mathrm{Leu}^{5}$ enkephalin.

${ }^{*} P=.001$ versus control, IPC-.

5-minute period of the preischemic working heart mode and also during the initial 5-minute periods of postischemic Langendorff and working heart perfusion periods. A standard enzymatic test based on spectrophotometric measurement of the amount of nicotinamide adenine dinucleotide phosphate was used (Granutest 2.5; Merck, Darmstadt, Germany). ${ }^{14}$

\section{Experimental Groups}

A total of 64 rats were assigned randomly to 1 of 4 experimental groups. Each group was divided into 2 subgroups, comprising 8 experiments with ischemic preconditioning and 8 experiments without. Animals in group 1 served as controls without pretreatment with DADLE or naloxone. Animals in group 2 received an 
ischemia

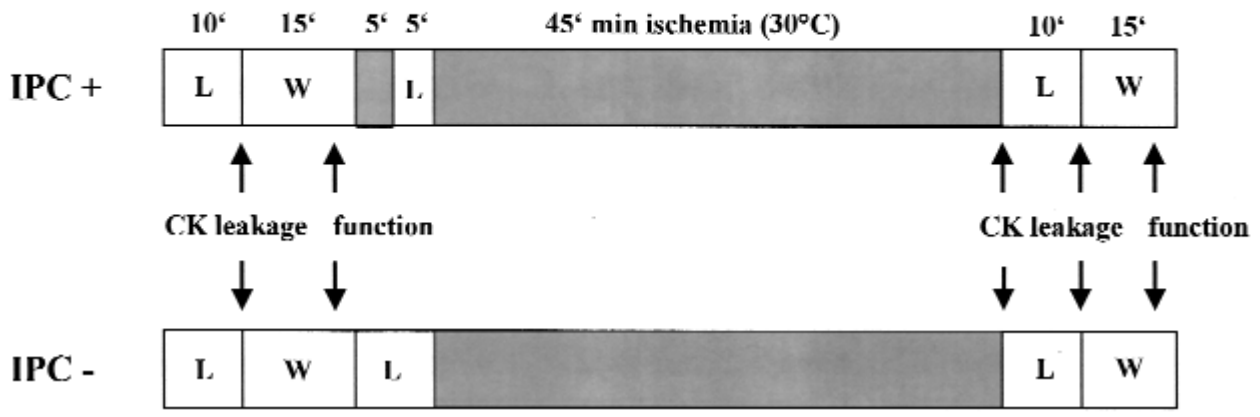

Figure 1. Experimental protocol of isolated heart perfusion. $L$, Langendorff perfusion; $W$, working heart perfusion; $I P C$, ischemic preconditioning. The upper scheme represents the protocol with ischemic preconditioning by one cycle of 5 minutes of global normothermic ischemia followed by 5 minutes of normothermic reperfusion before subsequent global hypothermic ischemia $\left(45\right.$ minutes at $\left.30^{\circ} \mathrm{C}\right)$. The lower scheme represents the perfusion protocol without ischemic preconditioning and 10 minutes of Langendorff perfusion instead. Myocardial function and creatine kinase (CK) leakage were assessed at the indicated time points.

injection of DADLE, $1 \mathrm{mg} / \mathrm{kg}$ body weight (Multiple Peptide Systems Inc, San Diego, Calif), during a 5-minute period by direct puncture of the tail vein 60 minutes before they were put to death and subsequent isolated heart perfusion was begun. Animals in group 3 received an intravenous injection of naloxone, $3 \mathrm{mg} / \mathrm{kg}$ body weight, 30 minutes before being put to death. Rats in group 4 received an injection of DADLE, $1 \mathrm{mg} / \mathrm{kg}$ body weight, by direct puncture of the tail vein, followed by injection of naloxone, 3 $\mathrm{mg} / \mathrm{kg}$ body weight, 60 minutes before being put to death.

\section{Expression of Results}

All results are expressed as mean \pm standard deviation. Preischemic values of cardiac function, including aortic flow, coronary flow, cardiac output, maximum left ventricular developed pressure, maximum rate of pressure rise ( $\mathrm{dP} / \mathrm{dtmax})$, heart rate, and coronary flow, are expressed in terms of absolute values, and indices of postischemic function are given as a percentage of their individual preischemic values. CK leakage in the coronary effluent, measured during the preischemic and postischemic perfusion periods, is expressed as international units per 5 minutes per heart.

\section{Statistical Analysis}

One-way analysis of variance with Bonferroni corrected $t$ test (for multiple comparisons) was used to detect differences between groups.

\section{Results}

Table 1 shows the absolute values for preischemic cardiac function. Differences observed between group means could be due to chance $(P>.2)$. Figure 2 and Table 2 show the recovery of cardiac function after 45 minutes of global hypothermic ischemia at $30^{\circ} \mathrm{C}$. Both pretreatment with DADLE and ischemic preconditioning improved the recovery of aortic flow when compared with untreated controls $(57.7 \% \pm 4.0 \%$ and $60.8 \% \pm 4.3 \%$ vs $40.0 \% \pm 4.2 \% ; P<$
.001). Pretreatment with DADLE before ischemic preconditioning further enhanced aortic flow recovery $(68.6 \% \pm$ $3.3 \%)$ above values obtained by ischemic preconditioning alone $(P=.038)$ and DADLE alone $(P<.001)$. A similar pattern was observed with regard to cardiac output. The effects of ischemic preconditioning, DADLE, and the combination thereof on recovery rates of aortic flow and cardiac output were counteracted by additional naloxone pretreatment. Analysis of the other postischemic functional parameters including heart rate, maximum left ventricular developed pressure, dP/dtmax, and coronary flow revealed differences among the study groups that could be due to chance $(P>.2)$.

There was no important difference in the CK leakage from preischemic hearts among any of the experimental groups $(P$ $>$.2) (Table 3). The immediate postischemic CK release during reperfusion in the Langendorff mode was increased in all hearts. During this phase, lowest CK values were measured after pretreatment with DADLE combined with ischemic preconditioning ( $P=.001$ vs untreated controls). In all groups involving additional pretreatment with naloxone, $\mathrm{CK}$ leakage did not differ markedly from that of untreated controls. Subsequent reperfusion in the working heart mode was followed by a decrease in the CK leakage in all experimental groups. No group-dependent differences were found during this period $(P>.2)$.

\section{Discussion}

Four results emerge from this study: (1) Pharmacologic activation of the $\delta$-opioid receptor by use of the synthetic opioid receptor agonist DADLE improves the postischemic aortic flow recovery of isolated working rat hearts exposed to 45 minutes of hypothermic ischemia at $30^{\circ} \mathrm{C}$. (2) This improve- 


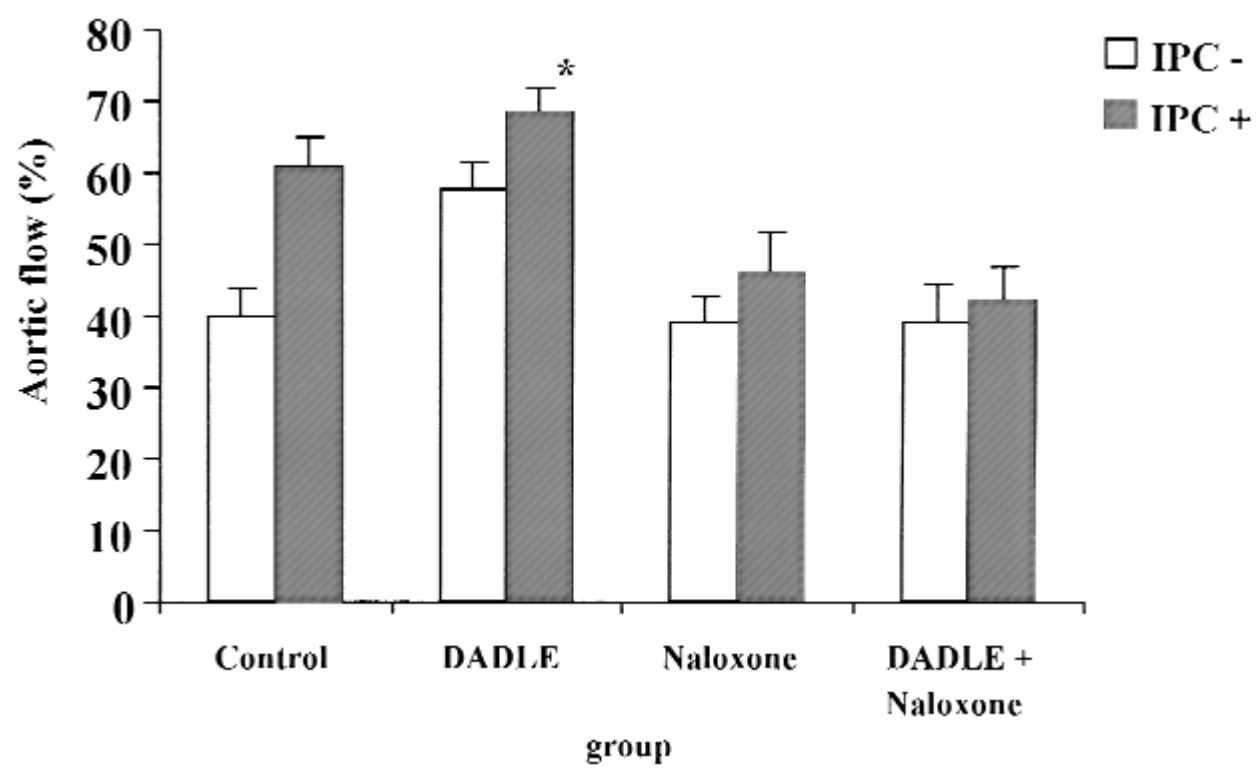

Figure 2. Recovery rates of aortic flow (in percentage of preischemic value). IPC, Ischemic preconditioning; DADLE, D-Ala ${ }^{2}-D-L e{ }^{5}$ enkephalin. * $P=.038$ versus "control IPC+"; means of groups "control IPC+," "DADLE IPC-," and "DADLE IPC+" were different from group means of all other groups $(P<.001)$.

ment is similar in extent to that conferred by a standard protocol of ischemic preconditioning. (3) Effects of either treatment can be blocked by the nonselective opiate receptor antagonist naloxone, a finding further supporting the hypothesis that the $\delta$-opioid receptor is involved in signaling of ischemic preconditioning. (4) Under selected experimental conditions, pharmacologic preconditioning by pretreatment with DADLE and ischemic preconditioning have additive beneficial effects with regard to postischemic functional recovery.

We have shown earlier that both a plasma fraction from hibernating animals (hibernation induction trigger) and the selective $\delta$-opioid receptor agonist DADLE similarly improve protection in animal models of multiorgan autoperfusion and cardioplegic arrest. ${ }^{15,16}$ The observation that opioid receptor antagonists such as naloxone or naltrexone reverse these changes supported the hypothesis that peripheral opioid receptors are involved in signal transduction occurring during natural hibernation. ${ }^{17}$ Subsequent studies in various experimental models revealed that natural and "artificial" hibernation induction triggers such as DADLE improve organ protection in experimental models relevant to clinical cardiac surgery, including heart and lung transplantation. ${ }^{8,18,19}$

Ischemic preconditioning, on the other hand, implies an endogenous mechanism by which a brief period of ischemia protects the tissues against adverse effects of a subsequent prolonged ischemic interval. ${ }^{1}$ Since the first description of this phenomenon by Murry and coworkers, ${ }^{1}$ protective capabilities of ischemic preconditioning have been demonstrated in a wide spectrum of animals and circumstances. ${ }^{20,21}$
Meanwhile, a variety of intracellular signaling pathways have been implicated in the protective effect of ischemic preconditioning. These include the activation of $\mathrm{G}$ protein-linked phospholipase $\mathrm{C}$-coupled receptors, tyrosine kinase pathways, protein kinase $\mathrm{C}$, and the generation of reactive oxygen species. ${ }^{22}$ Protection can be blocked at several stages, but due to inherent high redundancy of the receptor systems involved, alternative pathways may open up and preserve protection. Above that, it appears that there is a threshold to trigger preconditioning, which may vary depending on differential activation of adenosine, bradykinin, and also opioid receptors. ${ }^{23}$ Such a scheme would require that all receptor systems including the opioid-coupled transduction pathway use a common downstream signaling cascade, which emerges to reside in either a protein kinase $\mathrm{C}$-mediated or direct opening of adenosine triphosphate potassium $\left(\mathrm{K}_{\mathrm{ATP}}\right)$ channels, thereby preventing intracellular calcium overload. ${ }^{24,25}$ This finding, together with the previous evidence for the role of DADLE in the context of natural hibernation, indicated that the two seemingly unrelated entities of natural hibernation and ischemic preconditioning share signaling pathways involving peripheral $\delta$-opioid receptor activation.

In a recent report by Kevelaitis and colleagues, ${ }^{7}$ both phenomena were addressed in a single experimental study. Their work was directed to the cardioprotective transduction pathway further downstream from the activation of the $\delta$-opioid receptor. Evidence is provided that opening of the $\mathrm{K}_{\mathrm{ATP}}$ channels in fact is its final effector, since pretreatment with the $\mathrm{K}_{\mathrm{ATP}}$-channel blocker glibenclamide abolished the organ protective effects of both preconditioning and DADLE. 
Unlike previous studies, the present work focused on the functional consequences of both treatments, because from a clinical standpoint the quality of any kind of myocardial protection is estimated by its potential to regenerate postischemic cardiac function. In view of the limitations of nonworking heart systems, including the absence of external work to be performed against constant afterload and reduced oxygen requirements, the isolated working rat heart model was used. A protocol of unprotected global ischemia at moderate hypothermia was used.

We found that both protective measures, administration of DADLE and ischemic preconditioning, similarly improve the postischemic regeneration of the parameters "aortic flow" and "cardiac output." Pretreatment with DADLE before ischemic preconditioning further enhanced functional recovery, suggesting that the two measures have additive effects. Even though the $\delta$-opioid receptor is thought to be involved in both instances, it is conceivable that activation of another protective pathway that is not shared between ischemic preconditioning and treatment with DADLE accounts for additional protection. In this context, it warrants consideration that the beneficial effects of ischemic preconditioning may be induced not only by receptor-mediated pathways. Thus, it appears that oxygen-derived free radicals released during brief ischemia/reperfusion act as a nonreceptor trigger of preconditioning, involving a phospholipase $\mathrm{C}-$ and/or D-mediated mechanism. ${ }^{23}$ The other explanation may be related to the dosage of DADLE selected in this study. It is thus possible that the concentration of $1 \mathrm{mg} / \mathrm{kg}$ (usually considered to be a standard opiate dosage) given systemically 1 hour before organ retrieval was not high enough to activate myocardial $\delta$ opioid receptors quantitatively, thereby leaving an aliquot of receptors arousable for other appropriate signals such as the preconditioning signal. Dosage and the time interval between DADLE administration and isolated heart perfusion were selected according to previous evidence that (1) this concentration was effective in the rabbit heart, (2) pretreatment at a DADLE dosage of $10 \mathrm{mg} / \mathrm{kg}$ instead of $1 \mathrm{mg} / \mathrm{kg}$ resulted in pronounced bradycardia in our own pilot experiments, and (3) the protective effects of hibernation induction triggers similar to DADLE were lost when the time interval between in vivo preperfusion and organ ischemia was less than 1 hour. $^{9}$

Pretreatment with naloxone abrogated the improvement of aortic flow regeneration that was observed with DADLE, ischemic preconditioning, or the combination thereof. This observation further supports findings of Schultz, Hsu, and Gross $^{3}$ obtained in intact rat hearts, who reported that ischemic preconditioning and morphine-induced cardioprotection involve the $\delta$-opioid receptor.

The recovery rates of "aortic flow" were constantly lower than those of other parameters (maximum left ventricular developed pressure and $\mathrm{dP} / \mathrm{dtmax}$ ). This dissociation is explained by the fact that isolated hearts can generate a considerable rate of recovery in developed pressure, which still may not be high enough to overcome the afterload imposed in a working heart system.

The CK release pattern during early reperfusion in the Langendorff mode matched to the recovery rates of aortic flow inasmuch as $\mathrm{CK}$ values observed with the combination of DADLE and ischemic preconditioning were reduced, when compared with untreated control hearts $(P=.001)$. This would suggest, therefore, that the improved functional recovery induced by DADLE before ischemic preconditioning was a result of enhanced cell salvage. With naloxone pretreatment no such difference was measured in comparison with untreated controls, a finding that corresponds to the abrogation of functional improvement. The decrease in CK release that was observed in all experimental groups during working heart reperfusion in comparison with the previous Langendorff reperfusion reflects an "easing off" of the immediate postischemic $\mathrm{CK}$ washout. This may be attributed to normalization of coronary flow in combination with the regenerative effect of ongoing reperfusion. ${ }^{26,27}$

\section{Limitations of the Study and Concluding Comments}

There are many obvious differences between the isolated perfused rat heart and the human heart in situ. The limitations of this type include the lack of a physiologic peripheral component and aspects of metabolic, nervous, and hormonal control, because aqueous solutions free of red cells, protein, and fatty acids are used to perfuse the coronary arteries. In addition, time of reperfusion is limited as is the time for postischemic observations.

Preperfusion with DADLE was conducted in the intact animal, raising the possibility that the opioid receptors involved could be either central or peripheral and, if peripheral, cardiac or noncardiac in location. However, the similar beneficial results from previous studies in which in vitro preperfusion of the heart with DADLE was used suggest that in fact cardiac opioid receptors are involved. ${ }^{18}$ This issue was further clarified by Aitchison and colleagues, ${ }^{28}$ who demonstrated that the opioid receptors mediating classic ischemic preconditioning are also cardiac and not extracardiac. In view of this evidence, there is reason to assume that cardiac rather than extracardiac opioid receptors are involved in the current findings too.

It is conceivable that the additive effects observed after pretreatment with DADLE in combination with ischemic preconditioning depend on the dosage of DADLE or its protocol of administration. Thus, it remains to be determined whether additive effects persist with higher nontoxic concentrations of DADLE. However, we have observed that pretreatment with DADLE and ischemic preconditioning similarly improve postischemic cardiac regeneration in a clinically relevant and functionally oriented experimental model. This finding renders the former treatment a theoretical alternative to classic protocols of ischemic preconditioning. The search for such 
alternatives is of considerable relevance because safety concerns about inflicting an ischemic insult to the heart have limited the clinical applicability of ischemic preconditioning so far. In surgical practice, however, opioid receptor stimulation before the ischemic interval may be less effective than expected because of the widespread use of morphine and fentanyl in anesthesia. As previous studies have shown, both drugs may antagonize $\delta$-opioid receptor-mediated effects because they are $\mu$-opioid receptor agonists, thus negating the beneficial effects of $\delta$-receptor-activating agents. ${ }^{29}$ On the other hand, there is evidence that morphine itself has activity at the $\delta_{1}$-receptor, which implies beneficial effects with respect to myocardial protection. ${ }^{30}$ Conversely, the use of agonist/antagonist drugs to achieve myocardial protection could antagonize the analgesic effects of $\mu$-active agents like morphine or fentanyl. These potentially limiting aspects need to be taken into account before opiates are used for such purposes. In view of this, the recent results obtained with direct potassium channel openers are promising. ${ }^{7}$ Our findings support the search for similar pharmacologic interventions directed further downstream from the opioid receptor level, because we observed that the activation of the $\delta$-opioid receptor-mediated pathway bears the potential to enhance the postischemic functional regeneration of the heart.

We express our gratitude to $\mathrm{C}$. Abraham, $\mathrm{PhD}$, our consultant statistician for biostatistical review of the study.

\section{References}

1. Murry CE, Jennings RB, Reimer KA. Preconditioning with ischemia: a delay of lethal injury in ischemic myocardium. Circulation. 1986;74:1124-36.

2. Yellon DM, Baxter GF, Garcia-Dorado D, Heusch G, Sumeray MS. Ischaemic preconditioning: present position and future directions. Cardiovasc Res. 1998;37:21-33.

3. Schultz JJ, Hsu AK, Gross GJ. Ischemic preconditioning in the intact rat heart is mediated by $\delta_{1}$ - but not $\mu$ - or K-opioid receptors. Circulation. 1998;97:1282-9.

4. Oeltgen PR, Govindaswami M, Bishop PD, Bruce DS, Langston MD, Wedge $\mathrm{J}$, et al. The use of delta ${ }_{2}$ opioid agonists for myocardial ischemia protection. FASEB J. 2000;14:A14.

5. Dawe AR, Spurrier WA. A more specific characterization of the blood "trigger" for hibernation. Cryobiology. 1971;8:302-5.

6. Su TP, Oeltgen PR, Nuchols PA, Nilekani SP, Spurrier WA. Delta opioid receptor ligand selectively induced hibernation in summer active ground squirrels. Fed Proc. 1988;2:1074-6.

7. Kevelaitis E, Peynet J, Mouas C, Launay JM, Menasché P. Opening of potassium channels: The common cardioprotective link between preconditioning and natural hibernation? Circulation. 1999;99:3079-85.

8. Bolling SF, Su TP, Childs KF, Ning XH, Horton ND, Kilgore K, et al. The use of hibernation induction triggers for cardiac transplant preservation. Transplantation. 1997;63:326-9.

9. Bolling SF, Benedict MB, Tramontini NL, Kilgore KS, Harlow HH, $\mathrm{Su} \mathrm{TP}$, et al. Hibernation triggers and myocardial protection. Circulation. 1998;98(Suppl):II-220-4.
10. Miki T, Cohen MV, Downey JM. Opioid receptor contributes to ischemic preconditioning through protein kinase $\mathrm{C}$ activation in rabbits. Mol Cell Biochem. 1998;186:3-12.

11. Chien GL, Van Winkle DM. Naloxone blockade of myocardial ischemic preconditioning is stereoselective. J Mol Cell Cardiol. 1996;28,1895-900.

12. Ross BD. 5. Heart and skeletal muscle. In: Perfusion techniques in biochemistry: a laboratory manual in the use of isolated perfused organs in biochemical experimentation. Oxford: Oxford University (Clarendon) Press; 1972. p. 258-320.

13. Neely JR, Liebermeister H, Battersby EJ, Moegen HE. Effect of pressure development on oxygen consumption by isolated rat hearts. Am J Physiol. 1967;212:804-14.

14. Bergmeyer HU. Methods in enzymatic analysis. London: Academic Press; 1974. p. 1777.

15. Chien S, Oeltgen PR, Diana JN, Salley RK, Su TP. Extension of tissue survival time in multiorgan block preparation with delta opioid DADLE ([D-Ala ${ }^{2}$ D-Leu $\left.{ }^{5}\right]-$ enkephalin). J Thorac Cardiovasc Surg. 1994;107:964-7.

16. Schwartz CF, Georges AJ, Gallagher MA, Yu L, Kilgore KS, Bolling SF. Delta opioid receptors and low temperature myocardial protection. Ann Thorac Surg. 1999;68:2089-92.

17. Bruce DX, Cope GW, Elam TR, Ruit KA, Oeltgen PR, Su TP. Opioids and hibernation. I. Effects of naloxone on bear HIT's depression of guinea pig ileum contractility and on induction of summer hibernation in the ground squirrel. Life Sci. 1987;41:2107-13.

18. Bolling SF, Tramontini NL, Kilgore KS, Su TP, Oeltgen PR, Harlow $\mathrm{HH}$. Use of "natural" hibernation induction triggers for myocardial protection. Ann Thorac Surg. 1997;64:623-7.

19. Oeltgen PR, Horton ND, Bolling SF, Su TP. Extended lung preservation with the use of hibernation trigger factors. Ann Thorac Surg. 1996:61:1488-93.

20. Schott RJ, Rohmann ER, Braun ER, Schaper W. Ischemic preconditioning reduces infarct size in swine myocardium. Circ Res. 1990;66:1133-42.

21. Li GC, Vasquez JA, Gallagher KP, Lucchesi BR. Myocardial protection with ischemic preconditioning. Circulation. 1990;92:609-19.

22. O'Rourke B. Myocardial $\mathrm{K}_{\text {ATP }}$ channels in preconditioning. Circ Res. 2000;87:845-55

23. Baines C, Cohen MV, Downey JM. Signal transduction in ischemic preconditioning: the role of kinases and mitochondrial $\mathrm{K}_{\text {ATP }}$ channels. J Cardiovasc Electrophysiol. 1999;10:741-54.

24. Light PE, Sabir AA, Allen BG, Walsh MP, French RJ. Protein kinase $\mathrm{C}$-induced changes in the stoichiometry of ATP binding activate cardiac ATP-sensitive $\mathrm{K}^{+}$channels. Circ Res. 1996;79:399-406.

25. North RA, Williams JT, Surprenant A, Christie MJ. $\mu$ and $\delta$ receptors belong to a family of receptors that are coupled to potassium channels. Proc Natl Acad Sci U S A. 1987;84:5487-91.

26. Karck M, Rahmanian $P$, Haverich $A$. Ischemic preconditioning enhances donor heart preservation. Transplantation. 1996;62:17-22.

27. Engelman DT, Watanabe M, Engelman RM, Rousou JA, Kisin E, Kagan VE, et al. Hypoxic preconditioning preserves antioxidant reserve in the working rat heart. Cardiovasc Res. 1995;29:133-40.

28. Aitchison KA, Baxter G, Moneeb Awan M, Smith RM, Yellon DM, Opie LH. Opposing effects on infarction of delta and kappa opioid receptor activation in the isolated rat heart: implications for ischemic preconditioning. Basic Res Cardiol. 2000;95:1-10.

29. Oeltgen PR, Nilekani SP, Nuchols PA, Spurrier WA, Su TP. Further studies on opioids and hibernation: delta opioid receptor ligand selectivity induced hibernation in summer-active ground squirrels. Life Sci. 1988;43:1565-47.

30. Schultz JE, Hsu AK, Gross GJ. Morphine mimics the cardioprotective effect of ischemic preconditioning via a glibenclamide-sensitive mechanism in the rat heart. Circ Res. 1996;78:1100-4. 